\title{
Exploring the Virchow-Robin spaces function: A unified theory of brain diseases
}

\author{
Iype Cherian, Margarita Beltran, Ekkehard M. Kasper ${ }^{1}$, Binod Bhattarai, Sunil Munokami, Giovanni Grasso² \\ Department of Neurosurgery College of Medical Sciences, Bharatpur, Chitwan, Nepal, 'Department of Surgery, Beth Israel Deaconess Medical Center, \\ Harvard Medical School, Boston, MA 02215, USA, ${ }^{2}$ Section of Neurosurgery, Department of Experimental Biomedicine and Clinical Neurosciences (BIONEC), \\ University of Palermo, Palermo, Italy \\ E-mail: *Iype Cherian - drrajucherian@gmail.com; Margarita Beltran - margabeltranmarin@gmail.com; Ekkehard M. Kasper - ekasper@bidmc.harvard.edu; \\ Binod Bhattarai - Binodbhattarai@gmail.com; Sunil Munokami - Smunokami@gmail.com; Giovanni Grasso - Giovanni.grasso@unipa.it \\ *Corresponding author \\ Received: 05 May 16 Accepted: 13 June $16 \quad$ Published:07 October 16
}

\begin{abstract}
Background: Cerebrospinal fluid (CSF) transport across the central nervous system (CNS) is no longer believed to be on the conventional lines. The Virchow-Robin space (VRS) that facilitates CSF transport from the basal cisterns into the brain interstitial fluid (ISF) has gained interest in a whole new array of studies. Moreover, new line of evidence suggests that VRS may be involved in different pathological mechanisms of brain diseases.

Methods: Here, we review emerging studies proving the feasible role of VRS in sleep, Alzheimer's disease, chronic traumatic encephalopathy, and traumatic brain injury (TBI).

Results: In this study, we have outlined the possible role of VRS in different pathological conditions.

Conclusion: The new insights into the physiology of the CSF circulation may have important clinical relevance for understanding the mechanisms underlying brain pathologies and their cure.
\end{abstract}

Key Words: Alzheimer disease, chronic traumatic encephalopathy, cisternostomy, paravascular pathway, Virchow-Robin spaces

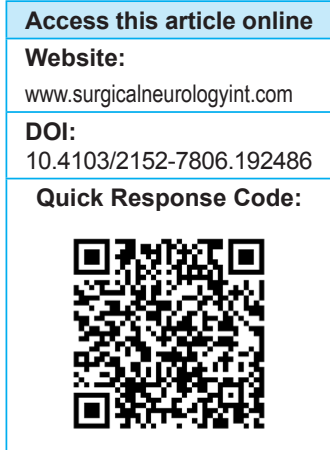

\section{INTRODUCTION}

The classic model of cerebrospinal fluid (CSF) homeostasis is based on the circulation theory where the majority of CSF is considered to be produced by the choroid plexus and circulates from the ventricles into the subarachnoid spaces. Recently, however, this circulation model has been reconsidered because it is supposed that CSF can be produced and absorbed throughout the entire CSF system, and the pericapillary Virchow-Robin space (VRS) plays a critical role in the CSF system. ${ }^{[29]}$

The CSF communication from the basal cisterns to the brain interstitial fluid (ISF) through the VRS has put a lot of things into perspective. Accordingly, it has opened new avenues into the pathophysiological mechanisms of many diseases. The implications are far reaching from sleep and insomnia, Alzheimer disease, chronic traumatic encephalopathy (CTE), to traumatic brain injury (TBI), among others.

This is an open access article distributed under the terms of the Creative Commons Attribution-NonCommercial-ShareAlike 3.0 License, which allows others to remix tweak, and build upon the work non-commercially, as long as the author is credited and the new creations are licensed under the identical terms.

For reprints contact: reprints@medknow.com

How to cite this article: Cherian I, Beltran M, Kasper EM, Bhattarai B, Munokami S, Grasso G. Exploring the Virchow-Robin spaces function:A unified theory of brain diseases. Surg Neurol Int 2016;7:S7 I -4.

http://surgicalneurologyint.com/Exploring-the-Virchow-Robin-spaces-function:-Aunified-theory-of-brain-diseases/ 
The VRS is seen around the vessels traversing from the cisterns into the brain. In 1851, Rudolph Virchow was the first to provide a detailed description of these microscopic spaces between the outer and inner/middle lamina of the brain vessels. ${ }^{[1]}$ Later, Charles-Philippe Robin confirmed these findings and was the first to describe the perivascular spaces as channels that exist in normal anatomy [Figure 1]. ${ }^{[37]}$

Over time, the clinical significance of VRS has changed as the understanding of its function has evolved. Perivascular spaces are thought to play an important role in maintaining neural homeostasis in an environment with high metabolic activity in a system lacking a true lymphatic pathway. ${ }^{[29]}$ According to some in vivo studies, it is believed that the brain's "protolymphatic" system begins with the production of CSF in the choroid plexus, which then travels into the subarachnoid space. ${ }^{[16,38]}$ From the subarachnoid space, the CSF is either cleared through the arachnoid granulations or it enters the parenchyma via the perivascular space, where it combines with interstitial fluid prior to exiting the brain. ${ }^{[16,38]}$ It has been pointed out that perivascular drainage may follow the normal direction of blood flow beginning with the penetrating arteries and arterioles to reach the terminal capillary beds and exiting along the paravenous routes. ${ }^{[16]}$ Other studies, however, have suggested that drainage occurs in the reverse direction to the flow of blood. ${ }^{[32,38]}$ Taken collectively, although there is no consensus regarding the directionality of drainage along these channels, such a perivascular drainage system may allow for the clearance of toxic metabolites within the brain parenchyma and possibly plays a role in the mechanisms underlying brain functions and diseases.

\section{SLEEP}

It is an unsolved question as to why humans and other animals are designed to sleep and what could be the

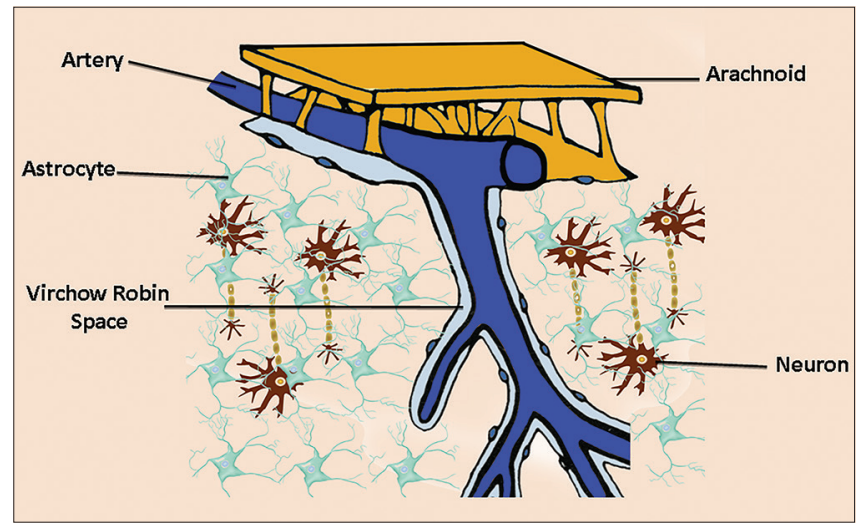

Figure I: Virchow-Robin spaces are perivascular, fluid-filled canals surrounding perforating arteries and veins in the parenchyma of the brain.Their complex anatomical structure allows a bidirectional fluid exchange between the brain extracellular space and the subarachnoid biological function for such an essential function. Although many studies have suggested that sleeping is important for memory function, ${ }^{[2,3,5]}$ the basic biological need for sleep is still uncertain. ${ }^{[34]}$ Recent studies have shown that during the sleep state the glymphatic activity is significantly increased, whereas its function is suppressed during wakefulness. ${ }^{[39]}$ Hence, such an observation indicates that during the sleep state the clearance of metabolites may be strongly enhanced allowing waste products produced during wakefulness to be eliminated. This finding is in agreement with other studies demonstrating synaptic plasticity and down-selection of synapses in association with sleep. ${ }^{[4,8]}$ The enlarged interstitial space volume during deep-wave sleep lowers the overall resistance to paravascular inflow, resulting in a sharp increase in CSF-ISF exchange and convective transport of waste solutes toward paravascular spaces surrounding large caliber cerebral veins for ultimate clearance via cervical lymphatic vessels. ${ }^{[39]}$

Furthermore, there are studies regarding the position of sleep and the direction of the head during sleep for maximum clearance. Interestingly, glymphatic transport seems to be most efficient in the recumbent, lateral position, especially on the right side. ${ }^{[20]}$ One possible explanation is that the heart is positioned higher when lying on the right side. This would facilitate the pumping of blood and the venous return possibly improving glymphatic influx.

These observations strongly support studies analyzing the metabolic products in samples from the basal cisterns and simultaneously in the jugular vein during the day.

\section{ALZHEIMER DISEASE}

CSF flow through the VRS, which has long been known as "interstitial flow" and believed to play a role equivalent to the lymphatic system, has recently regained substantial attention due to its relation to beta-amyloid clearance. ${ }^{[13]}$

The neuropathological findings in Alzheimer advocate the deposition of amyloid- $\beta(\mathrm{A} \beta)$, tau protein, and neurofibrillary tangles. ${ }^{[18]}$ Emerging evidence suggests that $A \beta$ clearance is impaired since the early stage of the disease, ${ }^{[23]}$ where both increase in $A \beta$ production ${ }^{[31]}$ and decrease in $A \beta$ clearance ${ }^{[30]}$ are considered to be contributing factors.

It is well-known that soluble $A \beta$ can be removed from the brain by various clearance systems, such as cellular uptake following enzymatic activity, transport across the blood-brain barrier (BBB) and blood-cerebrospinal fluid barrier, and ISF bulk flow. ${ }^{[33,36]}$

Although in the past the majority of extracellular $\mathrm{A} \beta$ was believed to be cleared by the $\mathrm{BBB},{ }^{[33]}$ recent studies have suggested that ISF bulk flow, through the astroglial aquaporin-4 channels of the glymphatic 
system, contributes to a larger portion of extracellular $A \beta$ clearance than previously considered. ${ }^{[21]}$

Because $A \beta$ deposition can be increased in presymptomatic individuals years before the characteristic symptoms of Alzheimer disease clearly appear, a better understanding of the glymphatic system may provide new insight into the pathogenetic mechanisms with diagnostic and therapeutic value.

\section{CHRONICTRAUMATIC ENCEPHALOPATHY}

CTE is a progressive neurodegenerative disorder caused by single or repetitive head trauma that does not result in observable neurological signs and symptoms of a concussion. ${ }^{[11,35]}$ It is pathologically distinct from other neurodegenerative diseases, including Alzheimer's disease. CTE has been reported in patients who have had repeated minor to moderate head injuries during contact sports and military activities ${ }^{[24,27]}$ and contact sport athletes who committed suicides. ${ }^{[28]}$ Deficits have been found in several functional domains including speed of information processing, memory, attention, and executive functions. ${ }^{[26]}$ Deficits in verbal learning and delayed recall have also been reported. ${ }^{[25,26]}$ Accordingly, CTE can be considered a distinct condition with respect to the acute sequelae of concussion or TBI. ${ }^{[10]}$ While postconcussive syndrome symptoms continue following an acute concussion without reaching a complete relief, the symptoms of CTE present years later following the trauma.

Neuropathology findings include pigment-laden histiocytes in the VRS, which may be accompanied by sparse lymphocytic seeding. ${ }^{[14,17]}$ Taken collectively, it can be argued that deposition of pigments and inflammation cells associated with blood degradation products (i.e. heme) may impair the VRS function. Considering the emerging role of the perivascular drainage system in the clearance of toxic metabolites within the brain parenchyma, the functional blockage of the VRS may be considered one of the mechanisms underlying CTE.

Further studies are warranted in order to detail the etiology of CTE and the role of the VRS.

\section{TRAUMATIC BRAIN INJURY}

Data from the literature show that TBI in the United States affects approximately 1.7 million people annually. ${ }^{[9]}$ Following TBI, the primary injury induces irreversible brain damage which is untreatable. The subsequent secondary injury plays a critical role in the clinical prognosis because without effective treatment it will provide additional tissue damage.

Brain edema plays a main role in the pathophysiology of TBI and contributes to the mortality found in these patients. ${ }^{[19]}$ General consensus exists in considering brain edema as an increase in fluid within the brain tissue and is regarded to be of vasogenic and cytotoxic types. Vasogenic edema results from BBB destruction that leads to fluid accumulation in the brain. Cytotoxic edema arises from fluid increase within cell cytoplasm as a result of injury. ${ }^{[22]}$ Recent evidence suggests that edema formation is also associated with CSF entrance into the brain parenchyma via the low-resistance para-arterial space or decreased interstitial fluid efflux or a combination of the two processes. ${ }^{[16]}$

It has been suggested that the glymphatic removal of excess interstitial fluid decreases following injury, ${ }^{[15]}$ allowing CSF to be shifted from the cerebral cisterns to the brain following TBI. One of the possible explanations for this rapid shift may be the traumatic subarachnoid bleed which causes a pressure gradient that is elevated in the cisterns and lower in the brain.

The fact that the cisterns are not seen in a scan of a patient with severe head injury along with a swollen brain may support such an occurrence. Fluid cannot be compressed and the amount of CSF (approximately $120 \mathrm{ml}$ ) contained in the cisterns cannot vanish anywhere in a short time. Furthermore, it cannot be shifted entirely into the spinal canal, as previously considered.

In this scenario, cisternostomy, a novel technique that incorporates the knowledge of skull base and microvascular surgery, has been recently proposed, and was found to decrease brain swelling, mortality, and morbidity. ${ }^{[6,7,12]}$ Opening the cisterns to atmospheric pressure, generous irrigation, and blood clot removal can provide a "back-shift" of CSF throughout the VRS, thereby reducing the intrabrain pressure. ${ }^{[6]}$ Opening the cisterns through a basal approach helps in reversing the flow through VRS, and this procedure, although technically demanding, will not result in brain herniation and stretch injury, which is often seen following decompressive hemicraniectomy. Such an emerging surgical procedure dealing with a tight and swollen TBI-affected brain is challenging and requires a thorough anatomic knowledge and adequate surgical experience. ${ }^{[6]}$

\section{CONCLUSION}

The understanding of VRS has been evolving and there is now a renewed interest in this field of research, especially after the glymphatic system has been described in humans.

In this study, we have outlined the possible role of VRS in different pathological conditions. Further studies are needed in order to clarify the role of the VRS in pathological conditions. 


\section{Financial support and sponsorship}

Nil.

\section{Conflicts of interest}

There are no conflicts of interest.

\section{REFERENCES}

I. [Rudolf Ludwig Karl Virchow]. Prensa Med Mex 1955;20:60-2.

2. Alger SE, Chambers AM, Cunningham T, Payne JD. The role of sleep in human declarative memory consolidation. Curr Top Behav Neurosci 20I5;25:269-306.

3. Ashworth A, Hill CM, Karmiloff-Smith A, Dimitriou D. Sleep enhances memory consolidation in children. J Sleep Res 2014;23:302-8.

4. Bushey D, Tononi G, Cirelli C. Sleep and synaptic homeostasis: Structural evidence in Drosophila. Science 201 I;332:1576-81.

5. Buzsaki G. Memory consolidation during sleep: A neurophysiological perspective. J Sleep Res 1998;7(Suppl I): 17-23.

6. Cherian I, Bernardo A, Grasso G. Cisternostomy for traumatic brain injury: Pathophysiological mechanisms and surgical technical notes. World Neurosurg 2016;29:5I-7.

7. Cherian I, Yi G, Munakomi S. Cisternostomy: Replacing the age old decompressive hemicraniectomy? Asian J Neurosurg 2013;8:132-8.

8. Cirelli C, Tononi G. Sleep and synaptic homeostasis. Sleep 2015;38:161-2.

9. Faul M, Sasser SM, Lairet J, Mould-Millman NK, Sugerman D. Trauma center staffing, infrastructure, and patient characteristics that influence trauma center need. West J Emerg Med 2015;16:98-106.

10. Gavett BE, Cantu RC, Shenton M, Lin AP, Nowinski CJ, McKee AC, et al. Clinical appraisal of chronic traumatic encephalopathy: Current perspectives and future directions. Curr Opin Neurol 201 I;24:525-31.

II. Gavett BE, Stern RA, McKee AC. Chronic traumatic encephalopathy: A potential late effect of sport-related concussive and subconcussive head trauma. Clin Sports Med 201 I;30:179-88.

12. Grasso G. Surgical Treatment for Traumatic Brain Injury: Is It Time for Reappraisal? World Neurosurg 2015;84:594.

13. Guerreiro R, Hardy J. Genetics of Alzheimer's disease. Neurotherapeutics 20|4; II:732-7.

14. Hay J, Johnson VE, Smith DH, Stewart W. Chronic Traumatic Encephalopathy: The Neuropathological Legacy of Traumatic Brain Injury. Annu Rev Pathol 2016; | |:2|-45.

15. Iliff J], Chen MJ, Plog BA, Zeppenfeld DM, Soltero M, Yang L, et al. Impairment of glymphatic pathway function promotes tau pathology after traumatic brain injury. J Neurosci 2014;34:16180-93.

16. Iliff J], Wang M, Liao Y, Plogg BA, Peng W, Gundersen GA, et al. A paravascular pathway facilitates CSF flow through the brain parenchyma and the clearance of interstitial solutes, including amyloid beta. Sci TransI Med 20 I2;4: I47 ra I I I .

17. Kanaan NM, Cox K, Alvarez VE, Stein TD, Poncil S, McKee AC. Characterization of Early Pathological Tau Conformations and Phosphorylation in Chronic Traumatic Encephalopathy. J Neuropathol Exp Neurol 2016;75:19-34.

18. Karch CM, Cruchaga C, Goate AM. Alzheimer's disease genetics: From the bench to the clinic. Neuron 20 I 4;83: I I-26.

19. Kleindienst A, Dunbar JG, Glisson R, Marmarou A. The role of vasopressin VIA receptors in cytotoxic brain edema formation following brain injury. Acta Neurochir 2013;155:151-64.

20. Lee H, Xie L, Yu M, Kang H, Feng T, Deane R, et al. The Effect of Body
Posture on Brain Glymphatic Transport. J Neurosci 2015;35: I 1034-44.

21. Louveau A, Smirnov I, Keyes TJ, Eccles JD, Rouhani SJ, Peske JD, et al. Structural and functional features of central nervous system lymphatic vessels. Nature 2015;523:337-41.

22. Marmarou A. A review of progress in understanding the pathophysiology and treatment of brain edema. Neurosurg Focus 2007;22:EI.

23. Mawuenyega KG, Sigurdson W, Ovod V, Munsell L, Kasten T, Morris JC, et al. Decreased clearance of CNS beta-amyloid in Alzheimer's disease. Science 2010;330: 1774.

24. McKee AC, Cantu RC, Nowinski C], Hedley-Whyte ET, Gavett BE, Budson AE, et al. Chronic traumatic encephalopathy in athletes: Progressive tauopathy after repetitive head injury. J Neuropathol Exp Neurol 2009;68:709-35.

25. McKee AC, Stein TD, Kiernan PT, Alvarez VE. The neuropathology of chronic traumatic encephalopathy. Brain Pathol 2015;25:350-64.

26. McKee AC, Stern RA, Nowinski CJ, Stein TD, Alvarez VE, Daneshvar DH, et al. The spectrum of disease in chronic traumatic encephalopathy. Brain 2013;136(Pt I):43-64.

27. Omalu B, Hammers JL, Bailes J, Hamilton RL, Kamboh MI, Webster G, et al. Chronic traumatic encephalopathy in an Iraqi war veteran with posttraumatic stress disorder who committed suicide. Neurosurg Focus 20I I;3 I:E3

28. Omalu BI, Bailes J, Hammers JL, Fitzsimmons RP. Chronic traumatic encephalopathy, suicides and parasuicides in professional American athletes: The role of the forensic pathologist. Am J Forensic Med Pathol 2010;31:130-2.

29. Oreskovic D, Klarica M. The formation of cerebrospinal fluid: Nearly a hundred years of interpretations and misinterpretations. Brain Res Rev 2010;64:24I-62.

30. Potter R, Patterson BW, Elbert DL, Ovod V, Kasten T, Sigurdson W, et al. Increased in vivo amyloid-beta42 production, exchange, and loss in presenilin mutation carriers. Sci Transl Med 2013;5:I89ra 177.

31. Reiman EM, Quiroz YT, Fleisher AS, Chen K, Velez-Pardo C, jimenez-Del-Rio M, et al. Brain imaging and fluid biomarker analysis in young adults at genetic risk for autosomal dominant Alzheimer's disease in the presenilin I E280A kindred: A case-control study. Lancet Neurol 20 12; I I:1048-56.

32. Schley D, Carare-Nnadi R, Please CP, Perry VH, Weller RO. Mechanisms to explain the reverse perivascular transport of solutes out of the brain. J Theor Biol 2006;238:962-74.

33. Shibata M, Yamada S, Kumar SR, Calero M, Bading J, Frangione B, et al. Clearance of Alzheimer's amyloid-ss (I-40) peptide from brain by LDL receptor-related protein-I at the blood-brain barrier. J Clin Invest 2000; 106: 1489-99.

34. Siegel JM. Clues to the functions of mammalian sleep. Nature 2005;437: I 264-7I

35. Stern RA, Daneshvar DH, Baugh CM, Seichepine DR, Montenigro PH, Riley DO, et al. Clinical presentation of chronic traumatic encephalopathy. Neurology 2013;81:1 | 22-9.

36. Tarasoff-Conway JM, Carare RO, Osorio RS, Glodzik L, Butler T, Fieremans $\mathrm{E}$, et al. Clearance systems in the brain-implications for Alzheimer disease. Nat Rev Neurol 2015; I 1:457-70.

37. Weed LH. Studies on Cerebro-Spinal Fluid. No. II: The Theories of Drainage of Cerebro-Spinal Fluid with an Analysis of the Methods of Investigation. J Med Res 19|4;31:21-49.

38. Weller RO, Djuanda E, Yow HY, Carare RO. Lymphatic drainage of the brain and the pathophysiology of neurological disease. Acta Neuropathol 2009;117:I-14.

39. Xie L, Kang H, Xu Q, Chen MJ, Liao Y, Thiyagarajan M, et al. Sleep drives metabolite clearance from the adult brain. Science 2013;342:373-7. 